\section{International Journal of Medical Research and Review}

\title{
A descriptive study on the hypertensive crisis in Visakhapatnam, Andhra Pradesh, India
}

\author{
Prakasa Rao S. ${ }^{1 *}$, Sweta Ramani S. ${ }^{2}$, Sai Kiran P. ${ }^{3}$, Kiran Prasad S. ${ }^{4}$ \\ DOI: https://doi.org/10.17511/ijmrr.2020.i06.02 \\ 1* Salla Surya Prakasa Rao, Professor, Department of General Medicine, NRI Institute of Medical Sciences, Visakhapatnam, Andhra Pradesh, \\ India. \\ 2 Salla Sweta Ramani, DNB(CTVS), Ex. Registrar, Department of Cardiothoracic Surgery, King George Hospital, Andhra Medical College, \\ Visakhapatnam, Andhra Pradesh, India. \\ 3 Pudi Venkat Sai Kiran, Post-Graduate, Department of General Medicine, NRI Institute of Medical Sciences, Visakhapatnam, Andhra \\ Pradesh, India. \\ 4 Siddanati Kiran Prasad, Internee, Department of General Medicine, NRI Institute of Medical Sciences, Visakhapatnam, Andhra Pradesh, \\ India.
}

Objective: The objective of the present study, A Descriptive study on Hypertensive Crisis in Visakhapatnam, India was to evaluate the modes of presentations, clinical profile, and spectrum of target organ damage in patients with hypertensive emergencies. Material and Methods: The study population included patients admitted in this hospital with severely elevated blood pressure with clinical or laboratory evidence of acute target organ damage. Result: The clinical and laboratory profile of 50 of these patients were evaluated. Males had higher chances of developing a hypertensive emergency compared to females. The commonest presenting symptoms were chest pain, dyspnoea, and neurological deficit. The majority of the patients have known hypertensives. Higher levels of blood pressure at presentation were associated with an adverse outcome. Acute LVF was the commonest target organ damage observed. In-hospital mortality of $14 \%$ was observed in the present study. Conclusion: Known hypertensives are at a higher risk of presenting with acute target organ damage associated with chest pain. Acute LVF is the commonest form of target organ damage encountered in the present study.

Keywords: Hypertensive Crisis, Hypertensive Emergency, Visakhapatnam

Corresponding Author

Salla Surya Prakasa Rao, Professor, Department of General Medicine, NRI Institute of Medical Sciences, Visakhapatnam, Andhra Pradesh, India.

Email: drssp56@gmail.com
How to Cite this Article

To Browse

Rao SSP, Ramani SS, Kiran PVS, Prasad SK. A descriptive study on the hypertensive crisis in Visakhapatnam, Andhra Pradesh, India. Int J Med Res Rev. 2020;8(6):386-391.

Available From

https://ijmrr.medresearch.in/index.php/ijmrr/article/ view/1230

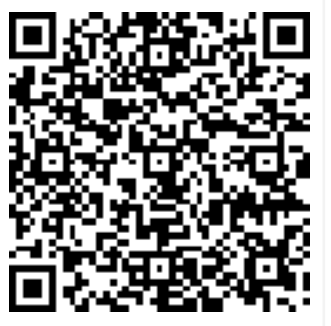

Manuscript Received 2020-12-04

Conflict of Interest No

Review Round 1
2020-12-14
Funding
Nil
(c) 2020 by Salla Surya Prakasa Rao, Salla Sweta Ramani, Pudi Venkat Sai Kiran, Siddanati Kiran Prasad and Published by
Siddharth Health Research and Social Welfare Society. This is an Open Access article licensed under a Creative Commons Attribution 4.0 International License https://creativecommons.org/licenses/by/4.0/ unported [CC BY 4.0]

$\begin{array}{cc}\begin{array}{c}\text { Review Round } 2 \\ 2020-12-20\end{array} & \text { Review Round } \mathbf{3} \\ \begin{array}{c}\text { Ethical Approval } \\ \text { Yes }\end{array} & \begin{array}{c}\text { Plagiarism X-checker } \\ 9 \%\end{array} \\ \text { Pudi Venkat Sai Kiran, Siddanati Kiran Prasad and Published by } \\ \text { his is an Open Access article licensed under a Creative Commons } \\ \text { tivecommons.org/licenses/by/4.0/ unported [CC BY 4.0]. }\end{array}$




\section{Introduction}

The study population included patients admitted in this hospital with severely elevated blood pressure with clinical or laboratory evidence of acute target organ damage. The clinical and laboratory profile of 50 of these patients were evaluated

Hypertension emergency or crisis is defined as severe hypertension i.e. diastolic pressure usually $>120 \mathrm{~mm} \mathrm{Hg}$ in patients with acute ongoing target organ damage.

Target organ damage:

- Heart- Left Ventricular Hypertrophy, angina or prior myocardial infarction, prior coronary revascularization, and heart failure

- Brain-Cerebro Vascular accident, Haemorrhagic Stroke or Ischemic attack

- Chronic kidney disease

- Peripheral arterial disease

- Retinopathy

\section{Materials and Methods}

The present study was done in patients admitted to NRI Institute of Medical Sciences, Sangivalasa, Visakhapatnam, and King George Hospital (Andhra Medical College) Visakhapatnam, Andhra Pradesh, over two years i.e. 1st April 2018 to 31st May 2020.

\section{Selection criteria:}

\section{Inclusion criteria:}

- Patients above the age of 18 years.

- Systolic blood pressure of $180 \mathrm{~mm}$ of $\mathrm{Hg}$ or diastolic blood pressure of $110 \mathrm{~mm}$ of $\mathrm{Hg}$

- Evidence of target organ damage, either clinically or on laboratory findings.

\section{Exclusion criteria:}

- Patients less than 18 years.

- Chronic renal failure, Valvular heart disease, other secondary causes of hypertension.

Source of data: Fifty patients were admitted to NRI Institute Of Medical Sciences and King George Hospital, Visakhapatnam, with clinical and laboratory evidence of a hypertensive emergency.

Type of study: Descriptive study.

Study protocol: Data were collected from fifty patients admitted to this hospital for over two years.
Patients who presented with an elevated blood pressure of systolic blood pressure of $>180 \mathrm{~mm}$ of $\mathrm{Hg}$ or diastolic blood pressure $>110 \mathrm{~mm}$ of $\mathrm{Hg}$, with a history of acute target organ damage or with laboratory evidence of acute target organ damage were included in the study.

A detailed history was taken which included presenting symptomatology, hypertension-related history with an emphasis on drug compliance. The information thus obtained was recorded in the proforma. Blood pressure was recorded in these patients at the time of admission, after one hour, after 24 hours, and 4 times a day during their stay in the hospital.

Detailed clinical examination was done in these patients with an examination of the respiratory system, cardiovascular system, abdomen, and central nervous system. Clinical examination also included fundoscopic examination in all the patients. Blood samples of these patients were evaluated for biochemical abnormalities.

The routine investigation done in these patients was the $\mathrm{HB} \%$, total WBC count, differential count, ESR, blood sugar, serum urea, serum creatinine, serum electrolytes, serum total cholesterol, serum triglycerides, HDL, LDL, microalbuminuria, and urine analysis. All the patients also underwent chest $\mathrm{x}$ ray, ECG, ECHO, Ultra Sonography of Abdomen, CT /MRI Brain, Urine analysis, and serum electrolytes. The collected data was analyzed using Microsoft Excel software.

\section{Results}

Results and analysis: Among the fifty patients in the present study, 31 (62 \% i.e. 31 out of 50 patients) were males. The male: female ratio is almost $1.6: 1$.

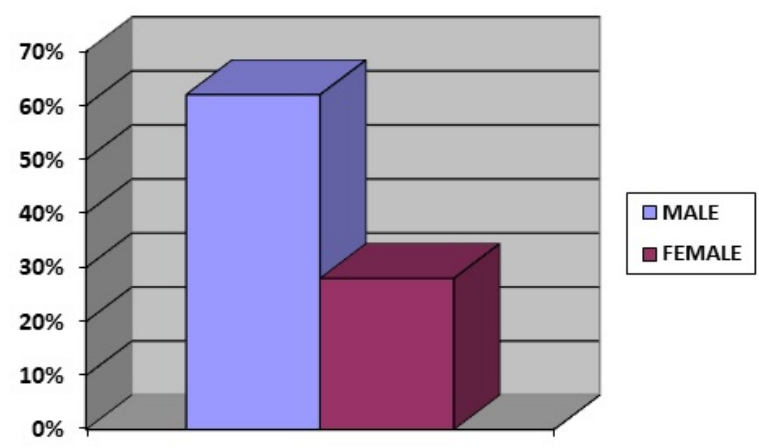


The mean age of the patients was 58 . The age varied from 38 to 70 in males and 39 to 78 in females. The mean age for males and females were 54 and 58.5 years respectively. The age distribution is given in table 2 below.

In the age distribution patients, patients less than the age of 50 were $34 \%$ (i.e. 17 out of 50 patients) and more than 50 years were $66 \%$ (i.e. 33 out of 50 patients).

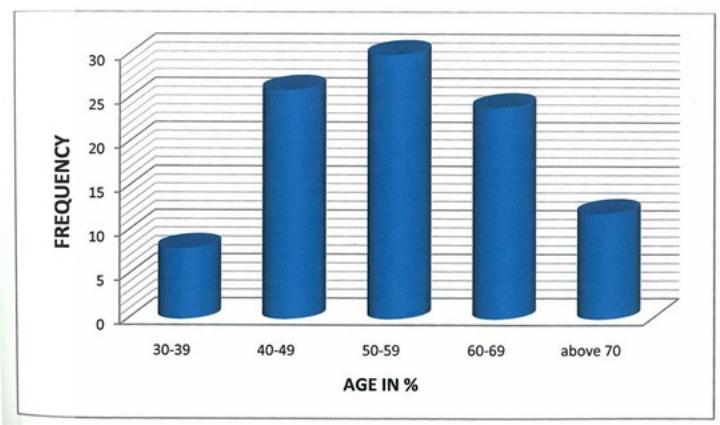

Fig-2: Age distribution.

In the present study, the presenting symptoms in these patients were chest pain, dyspnea, weakness in the limbs, and altered sensorium.

The commonest presenting complaints were dyspnea(36\%i.e, 18 out of 50 patients) and followed by neurological symptoms including weakness ( $28 \%$ i.e, 14 out of 50 patients)

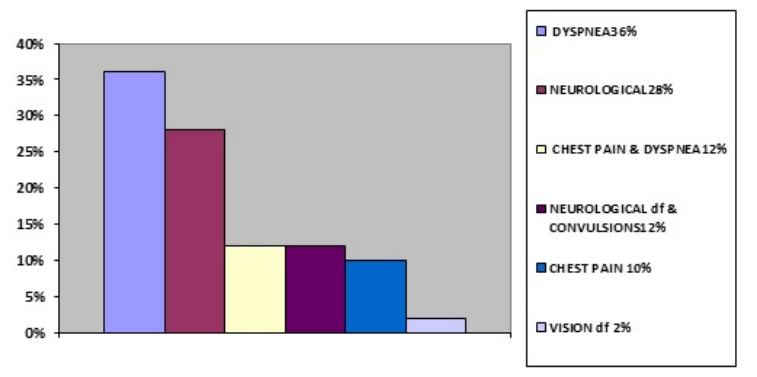

Fig-3: Presenting symptoms.

Among patients with neurological deficit, neurological damage included ischemic infarct $(20 \%$ i.e, 10 out of 50 patients), intracerebral hemorrhage ( $10 \%$ i.e, 5 out of 50 patients), SAH(6\%i.e, 3 out of 50 patients).

Among the target organ involvement acute LVF (26\% i.e, 13 out of 50 patients ), $\mathrm{ICH}(10 \%$ i.e, 5 out of 50 patients), ischemic infarct (20\% i.e, 10 out of 50 patients), MI ( $16 \%$ i.e, 8 out of 50 patients ),
Unstable angina ( $14 \%$ i.e, 7 out of 50 patients), SAH ( $6 \%$ i.e, 3 out of 50 patients), hypertensive encephalopathy( $4 \%$ i.e, 2 out of 50 patients), Vision defect ( $2 \%$ i.e, 1 out of 50 patients) were observed.

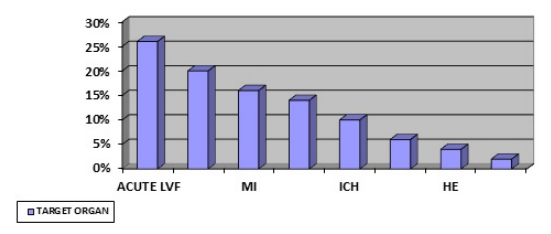

Fig-5: Target organ involvement.

\section{Hypertensive status:}

Among the patients 44 patients (88\%i.e, 44 out of 50 patients) were known hypertensives, the remaining patients ( $12 \%$ i.e, 6 out of 50 patients) were not a known hypertensive.

Of the 50 patients studied, 44 patients were known hypertensives, among them 27 patients(61\%) discontinued anti-hypertensives before the incident, remaining 17 patients (39\%) continued their medication.

Among the 50 patients, 30 patients (60\%) were having diabetes mellitus and 14 patients (28\%) had dyslipidemias.

Out of 50 patients with hypertensive emergencies, 7 patients died before discharge. Hospital mortality was $14 \%$ (i.e, 7 out of 50 patients). All expired patients had Intracerebral hemorrhage( $\mathrm{ICH}$ ) ( $10 \%$ i.e. 5 out of 50 patients ) and acute LVF ( $4 \%$ i.e. 2 out of 50 patients).

\section{Discussion}

In the present clinical study of hypertensive emergencies in NRI Institute Oof Medical Sciences, Visakhapatnam and King George Hospital (Andhra Medical College) Visakhapatnam, there is a male predilection for hypertensive emergencies. In the present study, 31 out of 50 patients are males.

The proportion of males in hypertensive emergencies were also higher in the study by Zampoglione et al [1]. This is probably due to an increased susceptibility of males to hypertensionrelated target organ damage. Gender differences in hypertension are due to biological and behavioral factors according to Sandberg and Ji [2]. The biological factors include sex hormones, chromosomal differences, and other biological sex differences that are protective against hypertension in women according to Vitale et al [3]. 
This is also because post-menopausal female hemodynamics is not very much different from the male profile about blood pressure. The majority of female patients belonged to the post-menopausal age group which shows susceptibility of postmenopausal age to end-organ damage.

Decade wise distribution of age shows the largest groups belonging to the fifth and sixth decade at the time of presentation with $30 \%$ (i.e, 15 out of 50 patients) and $26 \%$ (i.e, 13 out of 50 patients) respectively. According to Nguyen et al [4], almost $20 \%$ of young adults are hypertensive.

Analyzing the presenting symptoms, the largest group of patients in the present study presented with chest pain, dyspnea, and followed by the neurological deficit.

Zampglione et al in their study had more patients presenting with chest pain(36\%) and neurological deficit (28\%) respectively [1].

01. Rafighdoost MD, et al [5] study showed discontinuing of medications to be of utmost importance in precipitating the hypertensive crisis. $75 \%$ of the subjects had stopped medications and only $25 \%$ had continued them.

The majority of patients in the present study were previously known hypertensives ( $88 \%$ i.e, 44 out of 50 patients). Martin et al noticed a large number of patients $(83 \%)$ in their study to be previously diagnosed hypertensives [6].

The potential danger of hypertensive crisis is omnipresent. It can develop in patients with or without pre-existing chronic hypertension. Often the diastolic BP is $>120 \mathrm{~mm} \mathrm{Hg}$ but there is no specific threshold since it is the rapidity of the rise of $\mathrm{BP}$ and the absolute BP level which is more predictive(Eclampsia, acute Glomerulonephritis) [7].

The higher levels of blood pressure would have added to more severe target organ damage in these patients with an adverse outcome.

Evaluation of fundus revealed changes ranging from hypertensive retinopathy to papilledema in $50 \%$ of patients (i.e, 25 out of 50 patients). Papilledema is seen in $12 \%$ (i.e, 6 out of 50 patients) patients which is evidence of ongoing target organ damage.

Microalbuminuria was seen in $32 \%$ (i.e, 16 out of 50 patients)of the patients which put these patients at a higher risk for hypertension-related renal disease compared to the patients without proteinuria.
CT SCAN of the brain showed intracerebral hemorrhage as the commonest cause for the neurological target organ damage followed by cerebral infarct and subarachnoid hemorrhage. Voltage criteria suggestive of left ventricular hypertrophy on ECG was seen in $20 \%$ (i.e, 10 out of 50 patients) and $18 \%$ (i.e, 9 out of 50 patients) had left ventricular hypertrophy by echocardiography.

A study done by Lip GY et al on complications and survival of 315 patients with malignant hypertension found low median survival time in patients with proteinuria and high serum urea and serum creatinine levels at presentation and if left ventricular hypertrophy was detected on an electrocardiogram. These findings inpatients in a hypertensive emergency may help in prognosticating these patients [8].

Zampaglion et al report a large number, with 92\% of known hypertensives among their patients. This evidence confirms that hypertensive emergencies were higher in patients with previously known hypertension. This shows that patients with hypertension are at a higher risk of developing a hypertensive emergency, more so if they do not adhere to antihypertensive therapy [1].

In the present study, $61 \%$ (i.e, 31 out of 50 patients)among the known hypertensives ignored their hypertensive status and discontinued antihypertensive medications which would have put them at a higher risk for acute target organ damage and hypertensive emergency.

Diabetes mellitus and dyslipidemia were the other risk factors present in the present group of patients. Patients with diabetes mellitus and dyslipidemia were $28 \%$ and $28 \%$ respectively(i.e, 14 out of 50 patients).

Prevalence of arterial hypertension in diabetic patients is greater when compared with that in nondiabetic patients $(40 \sim 50 \%$ i.e, $20-25$ out of 50 patients and $20 \%$ i.e, 10 out of 50 patients respectively).

Metabolic abnormalities hyperglycemia, hyperinsulinemia, and dyslipidemia may play role in the pathogenesis and complications of arterial hypertension as seen in the present study.

In the present study, the highest systolic blood pressure recorded was $250 \mathrm{~mm} \mathrm{Hg}$ with a mean systolic blood pressure of $215 \mathrm{~mm} \mathrm{Hg}$. The highest diastolic blood pressure recorded was $160 \mathrm{~mm} \mathrm{Hg}$ with a mean of $130 \mathrm{~mm} \mathrm{Hg}$. 
It was noticed that the maximum number of patients with an acute rise of blood pressure was reported between $2 \mathrm{PM}$ to $4 \mathrm{PM}, 2 \mathrm{AM}-4 \mathrm{AM}$ and 10 AM-12 PM. A study by Martin J et al [6] reported a maximum number of cases between 6 AM to 12 PM. Zamapglione et al reported two peaks during the day i.e. 9 AM and 7 PM-8 PM [1]. Circannual peaks were noted in the study done by Salagre $\mathrm{Sb}$ et al in the hot and humid months of May and October [9].

Martin $\mathrm{J}$ et al6in their study reports mean systolic blood, the pressure of $193 \pm 26 \mathrm{~mm} \mathrm{Hg}$ in their patients, and mean diastolic blood pressure of $129 \pm 12 \mathrm{~mm}$ hg.

In a study done by De Jager RL et al [10], blood samples of patients were analyzed using mass spectrometry for Hypertension lowering medications. Poor adherence was detected in $80 \%$ of patients. Overall, patients took an average of only 2 anti-hypertensive medications despite being prescribed an average of 4 anti-hypertensive drugs.

Evaluation for target organ damage in patients in the present study were acute LVF (26\% i.e, 13 out of 50 patients) followed by ischemic infarct (20\% i.e, 10 out of 50 patients), acute myocardial infarction (16 \% i.e, 8 out of 50 patients), intracerebral haemorrhage $(10 \%$ i.e, 5 out of 50 patients), Sub arachnoid hemorrhage $(6 \%$ i.e, 3 out of 50 patients), hypertensive encephalopathy ( $4 \%$ i.e, 2 out of 50 patients) and vision defect( $2 \%$ i.e. 1 out of 50 patients).

Zamapglione et al [1] in their study observed target organ damage in the form of intracerebral hemorrhage $(4.5 \%)$ left ventricular failure (23\%) and acute ischemic stroke $(24 \%)$ in their patients. Pierin AMG, Flórido CF, Santos J [11] observed in their study that advanced age and neurological problems were associated with the hypertensive emergency.

Headache was associated with hypertensive urgency. Pain and emotional problems were associated with the hypertensive pseudo crisis. Our results can contribute to identifying patients with the hypertensive crisis who seek emergency services.

Shao PJ, et al [12] observed that in their cohort of adult patients with elevated blood pressure, the hypertensive crisis was associated with substantial morbidity and mortality, with the most vulnerable being those with the hypertensive emergency.
A study by Martin J et al [6] found that intracerebral hemorrhage $(17 \%)$ left ventricular failure $(25 \%)$, acute ischemic stroke (39\%), and acute myocardial infarction in $(8 \%)$ their patients. The outcome of the study showed in-hospital mortality of $14 \%$ (i.e, 7 out of 50 patients). All expired patients had Intracerebral hemorrhage ( $10 \%$ i.e. 5 out of 50 patients) and acute LVF ( $4 \%$ i.e. 2 out of 50 patients ).

\section{Conclusion}

The majority of patients presenting with hypertensive emergency belonged to the fifth and sixth decades of age. Males have higher chances of developing hypertensive emergencies compared to females. Known hypertensives are at a higher risk of presenting with acute target organ damage associated with a hypertensive emergency. The presence of diabetes mellitus and dyslipidemia increases the chance of developing a hypertensive emergency.

\section{What does the study add to the existing knowledge?}

The commonest mode of presentation is mostly dyspnea. Higher levels of blood pressure at presentation are seen with a neurological deficit also. Acute LVF is the commonest form of target organ damage encountered in the present study. The in-hospital mortality among these patients with hypertensive emergency is $14 \%$ (i.e, 7 out of 50 patients). The cause of mortality was intracranial hemorrhage (5 out of 50 ) and Left Ventricular failure ( 2 out of 50 ).

\section{Author's contribution}

Dr. Salla Surya Prakasa Rao: Concept, study design

Dr. Salla Sweta Ramani: Manuscript preparation

Dr. Pudi Venkat Sai Kiran: Statistical analysis

Dr. Siddanati Kiran Prasad: Manuscript preparation

\section{Reference}

01. Zampaglione B, Pascale C, Marchisio M, CavalloPerin P. Hypertensive urgencies and emergencies- prevalence and clinical presentation. Hypertension. 1996;27(1)144-7. doi: 10.1161/01.hyp.27.1.144 [Crossref] 
02. Sandberg $K$, Ji H. Sex differences in primary hypertension. Biol Sex Differ. 2012;3(1)1-21.

doi: $10.1186 / 2042-6410-3-7$ [Crossref]

03. Vitale C, Fini M, Speziale G, Chierchia S. Gender differences in the cardiovascular effects of sex hormones. Fundam Clin pharmacol. $2010 ; 24(6) 675-685$.

doi: $10.1111 /$ j.1472-8206.2010.00817.x [Crossref]

04. Nguyen QC, Tabor JW, Entzel PP, Lau Y, Suchindran C, Hussey JM, et al. Discordance in national estimates of hypertension among young adults. Epidemiology (Cambridge, Mass).2011;22(4)532-541.

doi: 10.1097/EDE.0b013e31821c79d2 [Crossref]

05. Rafighdoust A, Mohammadzadeh Shabestari M, Bostani T. A Study of Hypertensive Crisis and Precipitating Factors. Iranian Heart J. $2006 ; 7(4) 31-36$.

[Crossref]

06. Martin JF, Higashiama É, Garcia E, Luizon MR, Cipullo JP. Hypertensive crisis profile. Prevalence and clinical presentation. Arq Bras Cardiol.

2004;83(2)131-136. doi: 10.1590/s0066$782 \times 2004001400004$ [Crossref]

07. Kaplan NM. Hypertensive crisis in Kaplan AM, ed, Clinical hypertension, 11th edition. Lippincot Willams and Wilkins. 2015.

[Crossref]
08. Lip GY, Beevers M, Beevers DG. Complications and survival of 315 patients with malignantphase hypertension. J Hypertens. $1995 ; 13(8) 915-924$.

doi: $10.1097 / 00004872-199508000-00013$ [Crossref]

09. Salagre SB, Itolikar SM, Gedam K. A Prospective Observational Study to Determine the Prevalence and Clinical Profile of Patients of Hypertensive Crisis in a Tertiary Care Hospital. J Assoc Physicians India. 2017;65(6)14-21. [Crossref]

10. de Jager RL, de Beus $E$, Beeftink MM, Sanders MF, Vonken EJ, Voskuil $M$, et al. Impact of medication adherence on the effect of renal denervation- the SYMPATHY trial. Hypertension. 2017;69(4)678-684.

doi: $\quad$ 10.1161/HYPERTENSIONAHA.116.08818 [Crossref]

11. Pierin AMG, Flórido CF, Santos J. Hypertensive crisis- clinical characteristics of patients with hypertensive urgency, emergency and pseudocrisis at a public emergency department. einstein (São Paulo). 2019;17(4)eAO4685.

doi: $\quad 10.31744 /$ einstein_journal/2019A04685 [Crossref]

12. Shao PJ, Sawe HR, Murray BL, Mfinanga JA, Mwafongo V, Runyon MS. Profile of patients with hypertensive urgency and emergency presenting to an urban emergency department of a tertiary referral hospital in Tanzania. BMC Cardiovasc Disord. 2018;18(1)158.

doi: $\quad 10.1186 / \mathrm{s} 12872-018-0895-0 \quad$ [Crossref] 